\title{
Differential effects of $\alpha$-catenin on the invasion and radiochemosensitivity of human colorectal cancer cells
}

\author{
SARAH FÖRSTER ${ }^{1,2}$, STEPHANIE HEHLGANS ${ }^{3}$, FRANZ RÖDEL ${ }^{3-5}$, BENJAMIN OTTO $^{6,7}$ and NILS CORDES ${ }^{1,2,5,8,9}$ \\ ${ }^{1}$ Helmholtz-Zentrum Dresden-Rossendorf, Institute of Radiooncology - OncoRay, 01328 Dresden; \\ ${ }^{2}$ OncoRay - National Center for Radiation Research in Oncology, Faculty of Medicine and \\ University Hospital Carl Gustav Carus, Technische Universität Dresden, Helmholtz-Zentrum Dresden-Rossendorf, \\ 01307 Dresden; ${ }^{3}$ Department of Radiotherapy and Oncology, University of Frankfurt; ${ }^{4}$ German Cancer Consortium (DKTK), \\ partner site Frankfurt, 60590 Frankfurt; ${ }^{5}$ German Cancer Research Center (DKFZ), 69192 Heidelberg; \\ ${ }^{6}$ Eppendorf AG, 22339 Hamburg; ${ }^{7}$ Department of Internal Medicine, University Medical Center Hamburg Eppendorf, \\ 20246 Hamburg; ${ }^{8}$ Department of Radiotherapy and Radiation Oncology, Faculty of Medicine and \\ University Hospital Carl Gustav Carus, Technische Universität Dresden, 01307 Dresden; \\ ${ }^{9}$ German Cancer Consortium (DKTK), partner site Dresden, 69192 Heidelberg, Germany
}

Received December 4, 2017; Accepted January 31, 2018

DOI: $10.3892 /$ ijo.2018.4279

\begin{abstract}
Driven by genetic and epigenetic alterations, progression, therapy resistance and metastasis are frequent events in colorectal cancer (CRC). Although often speculated, the function of cell-cell contact for radiochemosensitivity, particularly associated with E-cadherin/catenin complex, warrants further clarification. In this study, we investigated the role of the E-cadherin/catenin complex proteins under more physiological three-dimensional (3D) cell culture conditions in a panel of CRC cell lines. In contrast to floating spheroids and growth in the laminin-rich matrix, collagen type 1 induced the formation of two distinct growth phenotypes, i.e., cell groups and single cells, in 5 out of the 8 CRC cell lines. Further characterization of these subpopulations revealed that, intriguingly, cell-cell contact proteins are important for invasion, but negligible for radiochemosensitivity, proliferation and adhesion. Despite the generation of genomic and transcriptomic data, we were unable to elucidate the mechanisms through which $\alpha$-catenin affects collagen type 1 invasion. In a retrospective analysis of patients with rectal carcinoma, a low $\alpha$-catenin expression trended with overall survival, as well as locoregional and distant control. Our results suggest that the E-cadherin/catenin complex proteins forming cell-cell contacts are mainly involved in the invasion, rather than the
\end{abstract}

Correspondence to: Professor Nils Cordes, OncoRay - National Center for Radiation Research in Oncology, Faculty of Medicine and University Hospital Carl Gustav Carus, Technische Universität Dresden, Fetscherstr. 74, PF 41, 01307 Dresden, Germany

E-mail: nils.cordes@oncoray.de

Key words: colorectal cancer, $\alpha$-catenin, radiochemotherapy, E-cadherin radiochemosensitivity of 3D grown CRC cells. Further studies are warranted in order to provide a better understanding of the molecular mechanisms controlling cell-cell adhesion in the context of radiochemoresistance.

\section{Introduction}

Colorectal cancer (CRC) is the third most common malignancy and fourth most common cause of cancer-related mortality worldwide (1). Despite effective multi-modal therapeutic options, metastatic $\mathrm{CRC}$ remains challenging to treat due to the amount of tumor burden and increasing resistance $(1,2)$. Among a plethora of genetic and epigenetic events eliciting tumor progression, it is well known that the loss of cell-cell contacts promotes local tumor infiltration and serves as a prerequisite for distant metastasis (3). Although often speculated, the function of cell-cell contacts for radiochemosensitivity warrants clarification as cell-cell contacts consist of numerous novel druggable targets.

Cell-cell contacts and adhesion are mediated by the homophilic interaction of E-cadherins on neighboring cells (4). Intracellularly, different adapter proteins, including $\beta$ - and $\gamma$-catenin bind to E-cadherin and $\alpha$-catenin, connecting these complexes to the actin cytoskeleton for adherens junction assembly (4). The dysregulation or loss of cell adhesion proteins, such as E-cadherin or $\alpha$-catenin is frequently found in carcinomas and has been shown to correlate with invasion and metastasis (5-8). Of clinical importance is the question of whether the loss of cell-cell contact affects the sensitivity of the cells to therapy. While early studies on floating tumor cell spheroids indicated a radioprotective impact of cell-cell adhesion, later studies addressing different cell-cell contact molecules, as well as studies on circulating tumor cells provided conflicting results with regards to radiochemosensitivity, invasion and cell-cell contacts mediated by integrins and intercellular adhesion molecule 1 (ICAM) (9-14). 
Owing to the difficulty which is encountered in the treatment of patients with late-stage metastatic CRC, in this study, we investigated the growth of a number of widely used CRC cell lines embedded in more physiological laminin-rich extracellular matrix (lrECM) or collagen type 1 (col-I), two abundantly expressed extracellular matrix (ECM) proteins in CRC (15-17). Furthermore, we made use of the $\alpha$-catenin deletion status of DLD-1 cells to address its impact on radiochemosensitivity and invasion into col-I.

\section{Materials and methods}

Antibodies and reagents. Antibodies against $\beta$-actin (A5441; Sigma-Aldrich, Taufkirchen, Germany), $\alpha$-catenin (3236S), $\beta$-catenin (9587), p- $\beta$-catenin S675 (4176S), TGF- $\beta$ (3709) (all from Cell Signaling Technology, Frankfurt am Main, Germany), E-cadherin (610181), fibronectin (610077) (both from BD Biosciences, Heidelberg, Germany), Zonula occludens-1 (ZO-1; 40-2300; Zymed Laboratories, San Francisco, CA, USA) and horseradish peroxidase-conjugated donkey antirabbit (NA934) and goat anti-mouse (NA9310) antibodies (GE Healthcare, Buckinghamshire, UK), as well as Alexa Fluor 488 and Alexa Fluor 594 secondary antibodies (A11001 and A1037; Invitrogen, Karlsruhe, Germany) were purchased as indicated. $\operatorname{lrECM}$ (Matrigel ${ }^{\mathrm{TM}}$ ) and col-I were from BD Biosciences, and 5-fluorouracil (5-FU) was from Medac (Wedel, Germany).

Cells and cell culture. The human CRC cell lines, DLD-1, HCT-15, HT-29, HCT-116, SW48 and SW480, were obtained from the American Type Culture Collection (ATCC, Manassas, VA, USA). The SW620 cells, originating from a lymph node metastasis of the same patient as the SW480 cell line, and the SW837 cells, were a kind gift from Dr J. Cinatl (University of Frankfurt, Germany). The cells were cultured in Dulbecco's modified Eagle's medium containing Glutamax-I supplemented with $1 \%$ non-essential amino acids (Sigma-Aldrich) and $10 \%$ fetal bovine serum (FBS; PAA, Cölbe, Germany) at $37^{\circ} \mathrm{C}$ in a humidified atmosphere containing $8.5 \% \mathrm{CO}_{2}$. All experiments were performed with asynchronous, exponentially growing cells.

Three-dimensional (3D) colony formation assay, 5-FU treatment and radiation exposure. 3D colony formation assay was performed as previously described $(18,19)$. For 3D colony formation, the cells were embedded in $0.5 \mathrm{mg} / \mathrm{ml} \mathrm{lrECM}$, $1 \mathrm{mg} / \mathrm{ml}$ col-I or a 1:1 mixture of both matrices. At $24 \mathrm{~h}$ after plating, the cells were treated with 5-FU as indicated or irradiated at room temperature using 2-6 Gy single doses of $200 \mathrm{kV}$ X-rays (Yxlon Y.TU 320; Yxlon, Copenhagen, Denmark; dose rate, $1.3 \mathrm{~Gy} / \mathrm{min}$ at $20 \mathrm{~mA}$ ). After cell line-dependent times (6-14 days) colonies ( $>50$ cells) were counted.

Matrix-switch experiments. The cells were embedded in 3D 1rECM or col-I, cultivated for 5 days, and retrieved by treatment with EDTA or collagenase (Merck, Darmstadt, Germany) followed by trypsinization. After counting using a microscope (Axiovert 40 C; Carl Zeiss Inc., Jena, Germany), the cells were embedded in the same or different matrices for 6-8 days.

Phenotype isolation. The DLD-1 cells were cultivated on top of 3D col-I for 8 days. Subpopulations exhibiting distinct phenotypes, namely the formation of cell clusters or single cell groups were isolated and further propagated to establish two separate cell lines (cell clusters, DLD-1 ${ }^{\alpha-c a t}$; and single cell groups, DLD-1 $\left.{ }^{\Delta \alpha-\text {-at }}\right)$.

siRNA, esiRNA and plasmid transfection. Transfection with siRNA, esiRNA and plasmids was performed with Oligofectamine or Lipofectamine 2000 (Invitrogen) as previously described (18). pcDNA3- $\alpha$-cat (20) was kindly provided by Dr C. Gottardi (Northwestern University, Chicago, IL, USA). E-cadherin and $\alpha$-catenin knockdown was performed with siRNA. siRNA E-cadh. \#2 (5'-CGAAUGUGGUACCUUUUG Att-3'; ID no. 146382) was from Applied Biosystems (Foster City, CA, USA), and siRNA E-cadh. \#3 (5'-GAGUGAAUUUUGAAG AUUGtt-3'; ID no. 44988) and siRNA $\alpha$-cat (5'-GGUUAC AACCCUUGUAAACtt-3'; ID no. 10582) were from Life Technologies (Carlsbad, CA, USA). Non-specific control siRNA (5'-GCAGCUAUAUGAAUGUUGUtt-3') was from Eurofins MWG Operon (Ebersberg, Germany). The knockdown of upregulated genes in the DLD-1 ${ }^{\Delta a-c a t}$ cells was performed with esiRNA (Eupheria Biotech, Dresden, Germany) against various target genes [alpha-2-macroglobulin (A2M), aldehyde dehydrogenase 1 family member L1 (ALDH1L1), FERM domain containing 4A (FRMD4A), guanylate binding protein 2 (GBP2), heat shock protein family $\mathrm{H}(\mathrm{Hsp} 110)$ member 1 (HSPHI), kallikrein related peptidase 7 (KLK7), laminin subunit alpha 2 (LAMA2), L3MBTL4, histone methyl-lysine binding protein (L3MBTL4), MTSS1, I-BAR domain containing (MTSS1), nectin cell adhesion molecule 3 (NECTIN3), NIMA related kinase 10 (NEK10), olfactomedin like 3 (OLFML3), oxidation resistance $1(O X R 1)$, ring finger protein 144B (RNF144B), ribosomal protein S6 kinase A6 (RPS6KA6), SH3 domain binding glutamate rich protein like (SH3BGRL), transmembrane protein 150A (TMEM150A) and very low density lipoprotein receptor $(V L D L R)]$. At $24 \mathrm{~h}$ following transfection, the cells were used for colony formation or invasion assays. The efficient knockdown or DNA delivery was confirmed at $48 \mathrm{~h}$ after transfection by western blot analysis.

Adhesion assay. For the evaluation of adhesion, the cells were plated on cell culture dishes pre-coated with col-I $\left(1 \mu \mathrm{g} / \mathrm{cm}^{2}\right)$. After $3 \mathrm{~h}$, non-attached cells were removed with phosphate-buffered saline (PBS) and the adherent cells were fixed with $70 \%$ ethanol and stained with Coomassie (AppliChem, Darmstadt, Germany) for microscopic evaluation (Axiovert $40 \mathrm{C}$; Carl Zeiss Inc.).

Proliferation assay. Equal cell numbers were seeded in 3D lrECM or col-I for $96 \mathrm{~h}$. The cells were retrieved by treatment with EDTA or collagenase followed by trypsinization and cell counting using a microscope (Axiovert $40 \mathrm{C}$; Carl Zeiss Inc.) (19).

Spheroid formation and 3D invasion assay. 3D invasion assay was performed as previously described (19). Briefly, spheroids were produced by seeding $10^{4}$ cells into agarose-coated round-bottom 96-well plates for 1-3 days. For 3D invasion, the spheroids were embedded into 3D col-I $(1 \mathrm{mg} / \mathrm{ml})$ and invasion was measured after 24 and $48 \mathrm{~h}$ using an Axiovert 200 microscope (Carl Zeiss Inc.). 
Immunofluorescence staining. For the localization of indicated proteins, immunofluorescence analysis was performed as previously described (18). Briefly, staining of the proteins of interest was performed with specific primary antibodies and fluorescence-labeled secondary antibodies and nuclei were stained with DAPI (Alexis, Grünberg, Germany). Representative immunofluorescence images were obtained using a Laser Scanning microscope LSM510 Meta (Carl Zeiss Inc.).

Total protein extracts and western blot analysis. Cells grown under 2D or 3D conditions for 24 to $96 \mathrm{~h}$ were lysed using modified RIPA buffer [50 mM Tris- $\mathrm{HCl}(\mathrm{pH} \mathrm{7.4)}$, $1 \%$ Nonidet-P40, $0.25 \%$ sodium deoxycholate, $150 \mathrm{mM} \mathrm{NaCl}$, $1 \mathrm{mM}$ EDTA, complete protease inhibitor cocktail (Roche, Mannheim, Germany), $1 \mathrm{mM} \mathrm{Na} \mathrm{VO}_{4}$ and $2 \mathrm{mM} \mathrm{NaF}$. Cell homogenization was performed with a 29-gauge needle and following centrifugation for $20 \mathrm{~min}$ at $13,000 \mathrm{x}$ the samples were stored at $-80^{\circ} \mathrm{C}$. SDS-PAGE, western blot analysis and the detection of specific proteins were performed as previously described $(18,19)$. Briefly, proteins were separated by SDS-PAGE and transferred onto nitrocellulose membranes (GE Healthcare). After blocking with 5\% non-fat dried milk powder (AppliChem) in PBS (Sigma-Aldrich) and subsequent incubation with primary and horseradish peroxidase-conjugated secondary antibodies (overnight at $4^{\circ} \mathrm{C}$ and $1.5 \mathrm{~h}$ at room temperature, respectively), the proteins of interest were detected with Amersham ECL Prime Western Blotting Detection Reagent (GE Healthcare). X-ray films were scanned (Epson Perfection 4490 Photo; Epson, Tokyo, Japan) and used for densitometric analysis.

Microarray-based genome and transcriptome analysis. DNA was isolated from DLD-1 subpopulations grown under 3D culture conditions according to the manufacturer's instructions using the NucleoSpin Tissue kit (Macherey-Nagel, Düren, Germany). Genomic analysis was performed using Affymetrix CytoScan HD Arrays (Affymetrix, Santa Clara, CA, USA). Affymetrix Chromosome Analysis Suite (ChAS) software was used for data processing and copy number aberration detection using the manufacturer's standard settings and array annotation database build 32.3. Gene expression profiles were measured as previously described (21). Total RNA was isolated from DLD-1 subpopulations grown under 3D culture conditions using the NucleoSpin RNA II kit (Macherey-Nagel) and used for transcriptome analysis using Affymetrix Human Transcriptome Arrays 2.0 and Affymetrix Human Genome U133 Plus 2.0 Arrays (Affymetrix). Procedures for cDNA synthesis, labeling, hybridization, washing and staining were carried out per the manufacturer's (Affymetrix) instructions and recommendations using the manufacturer's dedicated Reagent kits. Affymetrix Gene Expression Console (v.1.1) software was used for data processing using standard settings (quantile normalization, RMA correction). GenePattern software (Broad Institute, Cambridge, MA, USA) was used to reduce (collapse) multiple gene occurrences on the arrays via gene symbol to one signal per gene and sample. Microarray data are accessible on NCBI GEO under series accession number GSE109047. Differential gene expression was determined within each array platform using a t-test with unequal variance, a P-value threshold of 0.1 and a signal-log-ratio of 0.65. esiRNA transfection experiments were carried out to analyze the functional impact of some major candidates. Those candidates were selected through application of a more stringent P-value threshold of 0.05 observed in both array types and a signal-log-ratio of 0.65 in at least one type.

Patient characteristics, treatment and biopsy samples. Following an institutional review board approval [Ethics Committee of the University of Erlangen (approval no. 3085)] and after obtaining written informed consent, a total of 33 patients with locally advanced (UICC stage II/III) rectal adenocarcinoma were included in this study. The median age was 61.8 years with a range of 40 to 74 years. Within a prospective protocol (XELOX-RT) (22), all patients received pre-operative radiotherapy with $1.8 \mathrm{~Gy}$ single doses to a total dose of $50.4 \mathrm{~Gy}$. Capecitabine was administered concurrently at $825 \mathrm{mg} / \mathrm{m}^{2}$ twice daily on days 1 to 14 and 22 to 35 , and oxaliplatin $50 \mathrm{mg} / \mathrm{m}^{2}$ on days $1,8,22$ and 29 . Paraffin-embedded tissue specimens were obtained from pretherapeutic rectal biopsies routinely used for diagnostic purpose. Additionally, biopsies from pre-treated tumors were collected from 15 consecutive patients with informed consent for additional translational research on biopsy samples. Following the removal of portions needed for pathological evaluation, biopsies were immediately flash-frozen in liquid nitrogen, and stored until the extraction of mRNA.

Follow-up and criteria for relapse. Patients were re-evaluated at 3-month intervals for 2 years and every 6 months thereafter, for a total of 5 years. Proctoscopy (if the rectum was in place) was performed at 6-month intervals in the first year, and once a year thereafter. A follow-up schedule consisted of abdominal ultrasound (every 6 months for 2 years, then once per year for 3 years), computerized tomography of the abdomen and pelvis (3 months after completion of adjuvant treatment), and chest $\mathrm{X}$-rays (once a year for the first 3 years). Histological confirmation of locoregional and distant relapse was encouraged.

Microarray expression analysis in patient biopsies. A total of $10 \mu \mathrm{g}$ total RNA were used to prepare biotinylated cRNAs. The hybridization of $15 \mu \mathrm{g}$ labeled cRNA was performed on HG-U133A Affymetrix microarrays (Affymetrix) as previously described (23). All arrays were globally scaled to a target value of 1,000, and E-cadherin and $\alpha$-catenin mRNA values (Affymetrix Average Difference Units) were evaluated using Microarray Suite 5.0 software.

Immunohistochemical detection of E-cadherin, $\alpha$-catenin and scoring. Formalin-fixed, paraffin-embedded (FFPE) tissues from 33 patients were subjected to a staining procedure with DAKO EnVision ${ }^{\mathrm{TM}}$ FLEX peroxidase blocking reagent (K8000; Dako, Hamburg, Germany) and antigen retrieval via pre-treatment with citrate buffer $\mathrm{pH} 6.0$ (Abcam, Cambridge, UK) for $20 \mathrm{~min}$. The slides were then incubated with primary antibodies to either E-cadherin (1:400, ab40772) or $\alpha$-catenin (1:100, ab51032) (both from Abcam) for $120 \mathrm{~min}$ at room temperature. Following this, dextran polymer conjugated horseradish peroxidase and 3,3'-diaminobenzidine (DAB) chromogen was used for visualization and hematoxylin solution (Gill 3; Sigma-Aldrich, Munich, 
Germany) for counterstaining. Negative control slides in the absence of primary antibodies were included for each staining. Marker expression was evaluated semi-quantitatively by two independent investigators (F.R. and S.H.) without knowledge of the clinical characteristics. The percentage of positive tumor cells was assigned to one of the following categories: $0(<5 \%), 1(5-25 \%), 2(26-50 \%), 3(51-75 \%)$ and $4(>75 \%)$. The intensity of immunostaining was scored as follows: $1^{+}$(weak), $2^{+}$(moderate) and $3^{+}$(intense) and the percentages of positive tumor cells and staining intensity were then multiplied to produce an individual weighted score of 0-12.

Data analysis and statistics. Densitometric analysis of the results of western blot analysis was performed using ImageJ software (http:www.nih.gov). Unless indicated otherwise, the results are shown as the means \pm SD of 3 independent experiments. P-values are based on an unpaired, two-sided Student's t-test or one-way ANOVA and Dunnett's multiple comparisons test using Microsoft Excel 2010 or Prism 6 (GraphPad Software) and $\mathrm{P}<0.05$ was considered to indicate a statistically significant difference. Due to the limited number of patients and to facilitate further statistical analysis, the weighted histochemical scores were arbitrarily dichotomized: A score of $\leq 6$ was classified as 'low E-cadherin and low $\alpha$-catenin expression', and a score of $>6$ was classified as 'high E-cadherin and high $\alpha$-catenin expression'. Further endpoints of this study were actuarial overall survival rates as calculated using the method of Kaplan-Meier, and freedom from local relapse and distant disease. The level of significance was 0.05 (two-sided) in all statistical testing. Statistical analysis was performed using IBM SPSS version 21 software.

\section{Results}

CRC cell lines exhibit distinct morphologies in 3D culture. Since the growth of cancer cells in spheroids and in a $3 D$ matrix is well known to resemble physiological growth conditions $(24,25)$, we examined the capability of a panel of CRC cell lines to grow as free-floating multicellular spheroids (Fig. 1A). Whereas the DLD-1, HCT-15 and SW48 cells formed compact spheroids, the HT-29, HCT-116, SW480 and SW837 cells appeared as loose cell clusters. SW620, the only cell line derived from a lymph node metastasis of a CRC, failed to aggregate.

Due to their roles in spheroid formation and cell-cell adhesion, the expression of E-cadherin, $\alpha$-catenin and $\beta$-catenin was then determined. The expression and phosphorylation patterns of these proteins were heterogeneous among the tested CRC cell lines (Fig. 1B) and failed to correlate with spheroid formation capability (data not shown).

Based on the differences in tight versus loose spheroid formation and the fact that col-I is abundantly expressed in CRC and generally serves as a stimulus for the invasion of various types of cancer cells, including cells originating from CRC $(17,26)$ in this study, the cells were embedded in 3D col-I. With the exception of the SW837 cells, all CRC cell lines formed colonies in col-I. Of note, the DLD-1, HCT-15, HCT-116, SW480 and SW620 cells exhibited two distinct morphological phenotypes in col-I, namely cell clusters and groups of single cells (Fig. 1C and D).
To test for the matrix dependence of the formation of clusters or single cell groups, the cells were embedded into lrECM, a matrix consisting of various ECM proteins such as laminins and collagens. Of note, no single cell groups grew in lrECM, leading us to perform crossover experiments, in which the cells from lrECM were re-embedded into col-I and vice versa (Fig. 1E). While embedding the cells from either 1rECM or col-I into col-I led to 20-25\% single cell groups, re-seeding into lrECM induced the disappearance of single cells (Fig. 1E). We also depleted E-cadherin and found unaffected cell cluster/single cell group distributions (Fig. 1F and G). Of note, testing for markers of the epithelial-mesenchymal transition (EMT) (27) process, such as fibronectin, TGF- $\beta$ and ZO-1 indicated no EMT (data not shown). These findings indicate that the formation of cell clusters seems to be independent from E-cadherin, $\alpha$-catenin and $\beta$-catenin, and provide evidence as to the mechanisms through which col-I drives a phenotypical, EMT-unrelated change in some CRC cell lines. However, further experiments are warranted to fully elucidate the underlying mechanisms.

$\alpha$-catenin affects cell adhesion and invasion but not radiochemosensitivity. In line with other studies $(26,28,29)$, we isolated, propagated and characterized the two distinct DLD-1 subpopulations. The DLD-1 subpopulations grew either as compact cell clusters or as groups of single cells in 3D col-I (Fig. 2A). Our corroborative data further revealed the absence of $\alpha$-catenin in DLD-1 single cells in contrast to DLD-1 cell clusters (Fig. 2B) (26,29). Accordingly, the subpopulations were termed as DLD- $1^{\alpha-c a t}$ (epithelioid or forming cell clusters in col-I) and DLD-1 ${ }^{\Delta \alpha-c a t}$ (round or forming single cell groups in col-I). Despite a similar protein expression of E-cadherin and $\beta$-catenin in the two subpopulations (Fig. 2B), the staining of these proteins revealed an altered subcellular localization, i.e., physiological E-cadherin and $\beta$-catenin localization at the cell membrane in the DLD-1 ${ }^{\alpha-c a t}$ cells as opposed to cytosolic, peri-nuclear E-cadherin and $\beta$-catenin in the DLD- $1^{\Delta \alpha \text {-cat }}$ cells (Fig. 2C).

Connecting $\alpha$-catenin to the adhesion, invasion and radiochemosensitivity of CRC cells, we then investigated DLD-1 subpopulation behavior in and on 1rECM and col-I. Despite clear morphological differences, the DLD-1 subpopulations exhibited a similar proliferation in 3D 1rECM and col-I (Fig. 2D). Although not significantly different, the adhesion to col-I was less in the DLD-1 ${ }^{\alpha \text {-cat }}$ cells than in the DLD- $1^{\Delta \alpha-c a t}$ cells (Fig. 2E). By testing for 3D col-I invasion, we addressed the spheroid formation characteristics and invasion simultaneously. Whereas the DLD-1 $1^{\Delta \alpha-c a t}$ cells formed large disk-like spheroids, the DLD- ${ }^{\alpha-c a t}$ cells grew in small, round spheroids (Fig. 2F). Due to their improper cell-cell contacts, it was not surprising that the invasion distance covered by the DLD-1 ${ }^{\Delta \alpha \text {-cat }}$ cells was 5-fold greater than that of the DLD-1 $1^{\alpha \text {-cat }}$ cells (Fig. 2F and G). Moreover, basal clonogenic survival, sensitivity to radiation and treatment with 5-FU were found to be similar between $\alpha$-catenin wild-type and deleted cell populations (Fig. 3A-C). In agreement, $\alpha$-catenin silencing did not alter basal and radiation survival (Fig. 3D-F). These results clearly indicate that $\alpha$-catenin is pivotal for invasion more than for adhesion, but is clearly not pivotal for the radiochemosensitivity of DLD-1 CRC cells. 

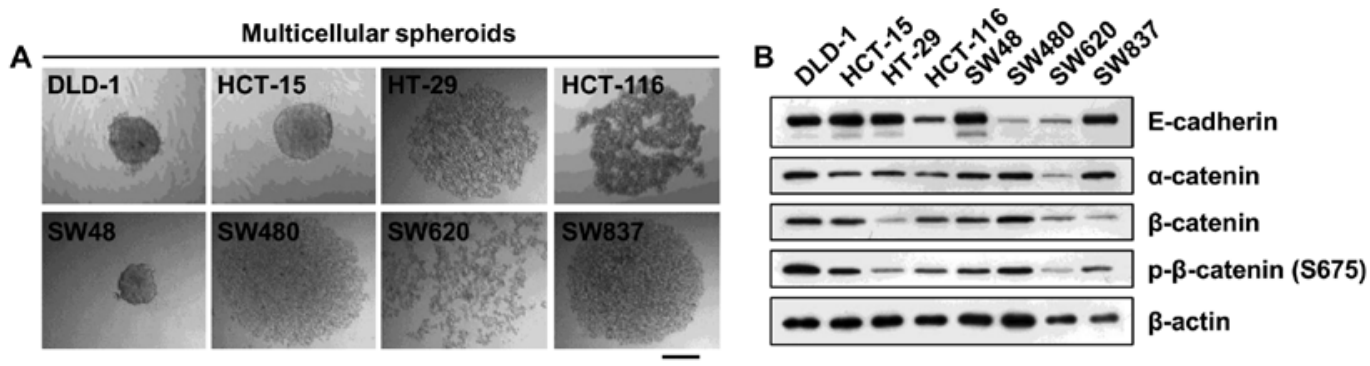

C

$200 \mathrm{~mm}$

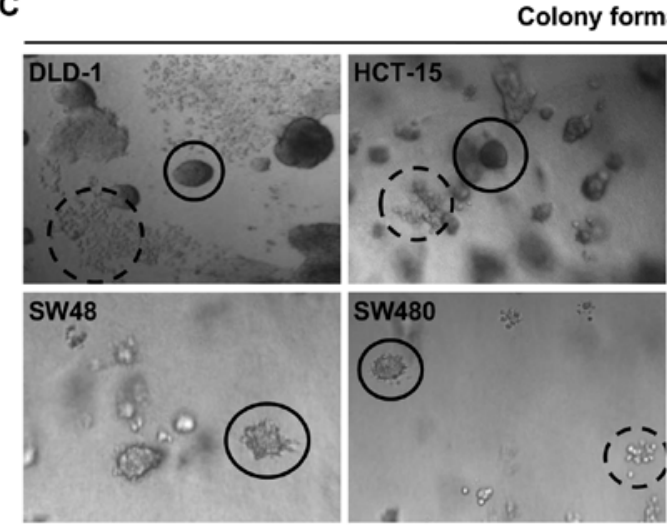

tion in Col-I

D

\begin{tabular}{|c|c|c|c|c|c|c|c|c|}
\hline cell line & DLD-1 & HCT-15 & HT-29 & НСТ-116 & SW48 & SW480 & SW620 & SW837 \\
\hline cell cluster & + & + & + & + & + & + & + & - \\
\hline $\begin{array}{l}\text { single cell } \\
\text { groups }\end{array}$ & + & + & - & + & - & + & + & - \\
\hline
\end{tabular}

E

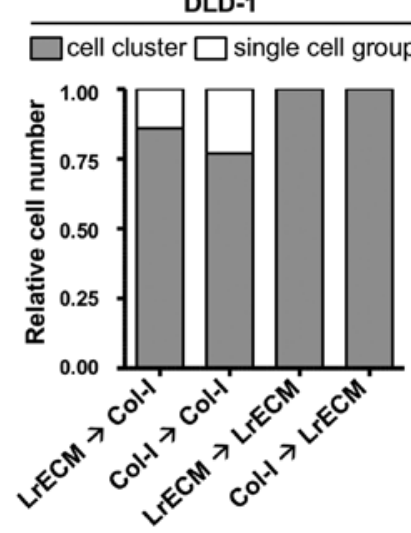

$\mathbf{F}$

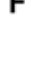

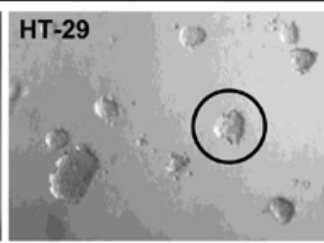

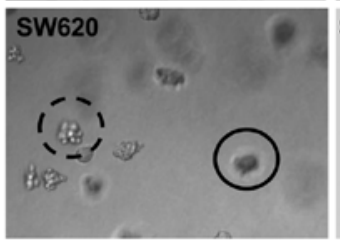

- - - single cell groups

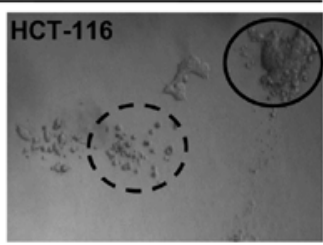

SW837

no colony formation

G DLD-1 $\square$ cell cluster $\square$ single cell groups

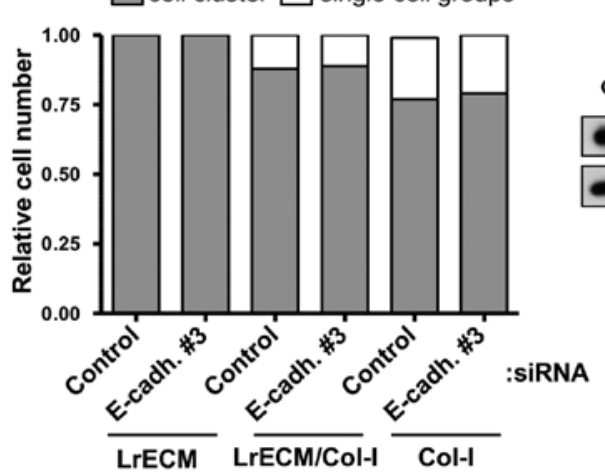

Figure 1. Colorectal cancer (CRC) cell lines exhibit distinct phenotypes when cultured in 3D. (A) Phase-contrast images of CRC free-floating spheroids at $24 \mathrm{~h}$ after seeding. (B) Representative western blots of cell-cell contact proteins in CRC cell line panel. (C) Phase-contrast images of CRC cells grown in col-I indicates two distinct phenotypes (cell clusters vs. single cell groups) in DLD-1, HCT-15, HCT-116, SW480 and SW620, but not HT-29 and SW48 cells. (D) Summary table of CRC phenotypes in col-I. (E) For crossover experiments, DLD-1 cells are firstly embedded in lrECM or col-I prior to re-plating in the same or other matrix. Results represent the mean values of 3 experiments. (F) The depletion of E-cadherin had no effect on the morphology of the DLD-1 cells in various 3D matrices. Experiments were performed in triplicate. (G) Representative western blots showing successful E-cadherin knockdown.

DNA copy number changes and differential gene expression in DLD-1 subpopulations. In addition to what is already known about DLD-1 subpopulations (26,28-31), we determined DNA copy number changes and performed transcriptome and genome analysis. We found the loss of the CTNNA1 gene located on chromosome 5 in the DLD-1 ${ }^{\Delta \alpha-c a t}$ cells as opposed to the DLD-1 ${ }^{\alpha-\text { cat }}$ cells. The FCRL6, SLAMF8, Clorf204, VSIG8, $C C D C 19$ genes on chromosome 1, as well as the PARD3B gene on chromosome 2 revealed increased DNA copy numbers in the DLD-1 ${ }^{\Delta \alpha-\text { cat }}$ cells compared with the DLD- ${ }^{\alpha-\text { cat }}$ cells. By contrast, FRMD5, MFAP1, PIN4P1, SERF2-C15ORF63, WDR76 and C15orf63 on chromosome 15, as well as CADPS2 
A
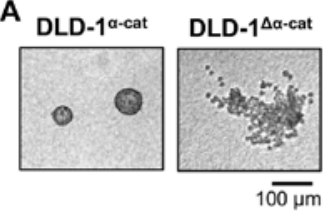

B

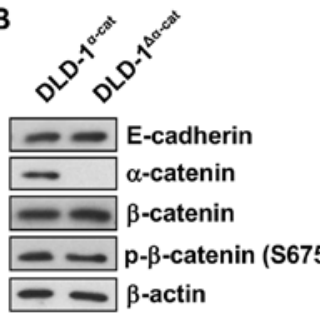

E

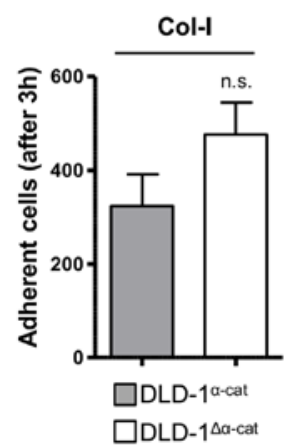

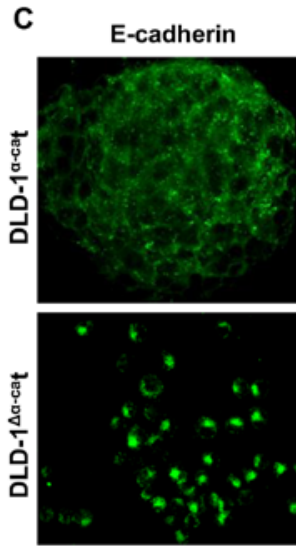

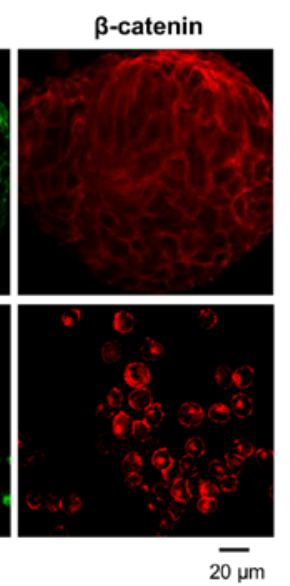

$\mathbf{F}$<smiles>[Te]</smiles>

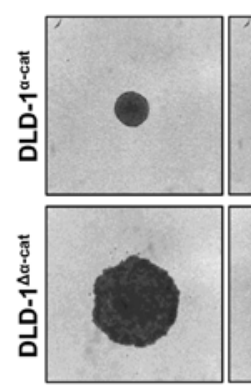

24

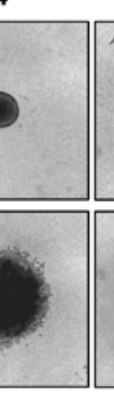

48 (hours)

G

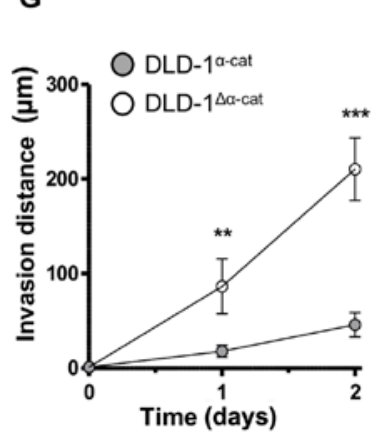

Figure 2. DLD-1 subpopulations display an altered morphology and invasion in 3D. (A) Phase-contrast images of the DLD-1 subpopulation grown in col-I. The DLD-1 $1^{\text {a-cat }}$ cells (left panel) grew as round colonies, while the DLD-1 ${ }^{\Delta a-\text {-at }}$ cells (right panel) grew as single cell groups. (B) Representative western blots of cellcell contact proteins in DLD-1 subpopulations. (C) Fluorescence images indicate differential localization of E-cadherin (left panel) and $\beta$-catenin (right panel) in DLD-1 subpopulations. (D) Relative proliferation rates of DLD-1 subpopulation cultured in either lrECM or col-I. (E) Adhesion of DLD-1 subpopulations on col-I-coated plates. (F) Representative phase-contrast images of spheroids embedded in col-I and invasion at different time-points. (G) Invasion distance of DLD-1 subpopulations at the indicated time-points. Results represent the means $\pm \mathrm{SD}\left(\mathrm{n}=3 ;{ }^{* *} \mathrm{P}<0.01 ;{ }^{* * *} \mathrm{P}<0.001 ; \mathrm{n} . \mathrm{s}\right.$., not significant).

and TAS2R16 on chromosome 7 indicated the loss or gain in the DLD-1 ${ }^{\alpha-\text { cat }}$ cells (Fig. 4A).

Comparing the DLD-1 subpopulations, we identified a number of differentially expressed genes (Fig. 4B). The genomic alterations described above are also observed at the transcription level, e.g., CTNNAl was downregulated, while FRMD5 was upregulated in the DLD-1 ${ }^{\Delta a-c a t}$ cells. Among the upregulated genes, we identified $S 100 A 4$ as a $\beta$-catenin target gene (Fig. 4B). Among the downregulated genes, we found the $\beta$-catenin target genes, $L G R 5$ and $A B C B 1$ (Fig. 4B).

Targeting of differentially expressed genes fails to modify the invasive phenotype of $D L D-1^{\Delta-c a t}$ cells. Unexpectedly, the knockdown or reconstitution of $\alpha$-catenin in the DLD-1 $1^{\alpha-\text { cat }}$ or DLD-1 ${ }^{\Delta \alpha-\text { cat }}$ cells, respectively, only marginally affected the spheroid size, but had no effect on invasion (Fig. 5A-D). Based on the identified transcriptomic alterations in the DLD-1 ${ }^{\Delta \alpha-\text { cat }}$ cells compared with the DLD-1 $1^{\alpha-c a t}$ cells, we performed the knockdown of a subset of elevated genes to discover essential drivers of the DLD-1 $1^{\Delta a-c a t}$ invasive phenotype. As CTNNAl was the only gene deleted in both alleles, the changes in the transcriptome may at least be partially influenced by this genetic phenotype. Of note, the targeting of these genes had no effect on either spheroid formation (Fig. 5E) or on the invasive capacity of the DLD-1 ${ }^{\Delta a-c a t}$ cells (Fig. 5F). Thus, our data suggest no critical impact of the overexpressed genes on DLD-1 ${ }^{\Delta a-c a t}$ cell invasion.
$E$-cadherin and $\alpha$-catenin expression in rectal carcinoma. Despite our observations, which lack a clear connection between CRC cell behavior and therapy responsiveness, we then stained rectal cancer biopsies for E-cadherin and $\alpha$-catenin, as neoadjuvant chemoradiotherapy comprises part of the standard therapy for advanced stages of rectal cancer (Fig. 6A). Astonishingly, E-cadherin and $\alpha$-catenin inversely correlated with the clinical endpoints, overall survival (Fig. 6B), locoregional control (Fig. 6C) and distant control (Fig. 6D). Assuming a cooperative and tumor progression- and spreading-impairing function of E-cadherin and $\alpha$-catenin (8), the association between low $\alpha$-catenin expression and low survival seems more logical. Thus, our data indicated that a low $\alpha$-catenin expression trended with a lower overall survival and lower locoregional control, and significantly correlated with a lower distant control. By contrast, high E-cadherin expression levels significantly correlated with all three measured endpoints, i.e., overall survival, locoregional and distant control (Fig. 6B-D).

\section{Discussion}

Novel therapies for late-stage, metastatic CRC are urgently required. As the mechanisms of the metastatic process require further elucidation, we, as well as others have made use of distinct subpopulations appearing in CRC cell lines when grown 2D as well as in matrix $(26,28,29)$. Due to their depletions in cell-cell 


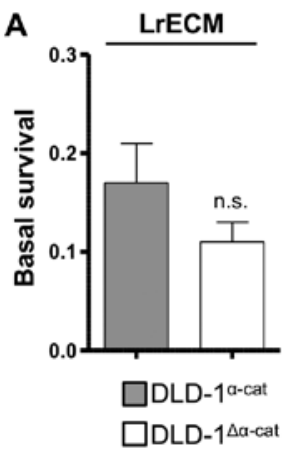

D

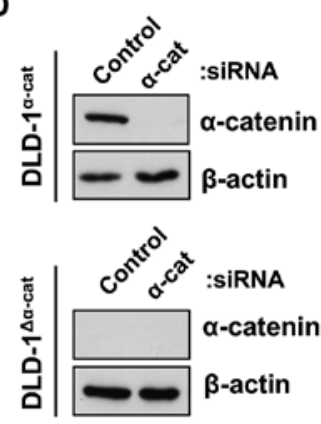

B

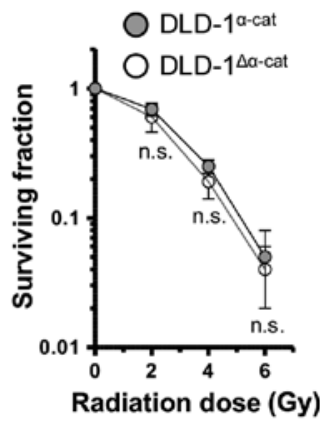

$\mathbf{E}$

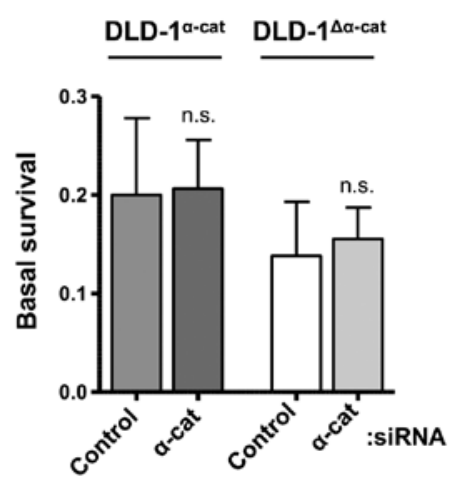

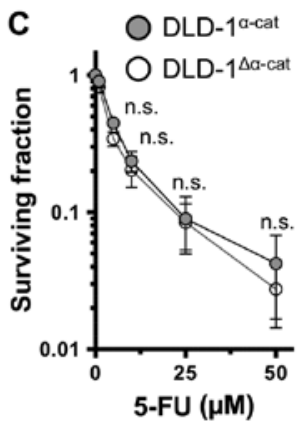

$\mathbf{F}$

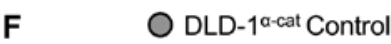

$\triangle$ DLD-1 ${ }^{\alpha-c a t} \operatorname{siRNA} \alpha-c a t$

O DLD-1 1 a-cat Control

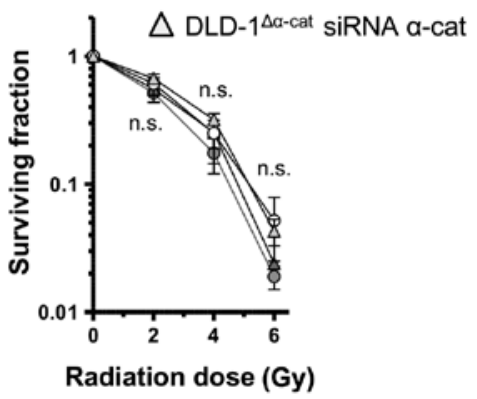

Figure 3. Deletion of $\alpha$-catenin has no effect on the radiochemosensitivity of DLD-1 subpopulations. (A) Basal clonogenic survival, (B) radiation survival, and (C) survival following 5-FU treatment of DLD-1 subpopulations cultured in $1 \mathrm{rECM}$. Results represent the means \pm SD ( $\mathrm{n}=3$; n.s., not significant). (D) Representative western blots, (E) basal clonogenic survival and (F) radiation survival of DLD-1 subpopulations after siRNA-mediated $\alpha$-catenin knockdown (means $\pm \mathrm{SD} ; \mathrm{n}=2-3$; n.s., not significant).

contact molecules, these cell lines are valuable tools which may be used to investigate the associated molecular mechanisms. In this study, we employed CRC cell lines, including DLD-1, which present an $\alpha$-catenin null phenotype. In our study addressing the radiochemosensitivity of 3D grown CRC cell populations and invasion, the following findings were obtained: i) Differential, col-I-induced 3D growth phenotypes in the CRC cell line panel; ii) a significant distinction in the invasion, but not the adhesion, proliferation and radiochemosensitivity of DLD-1 $1^{\alpha-\text { cat }}$ compared to the DLD-1 $1^{\Delta \alpha \text {-cat }}$ cells; iii) an ineffectiveness to impair col-I invasion by the targeting of genes highly overexpressed in DLD-1 ${ }^{\Delta \alpha \text {-cat }}$ cells; and iv) low levels of $\alpha$-catenin correlating with a worse prognosis following the chemoradiation of patients suffering from rectal carcinomas.

Alterations of transmembrane and cytosolic compounds critical for cell-cell contact assembly are frequent events in cancer $(32,33)$. Numerous studies have demonstrated that cellcell contact molecules, such as $\alpha$-catenin and E-cadherin are downregulated in CRC (34,35), cervical carcinoma (36), oral carcinoma (37), as well as other types of cancer. Similar to other cancer types, ECM proteins, such as laminin and col-I are overexpressed in CRC and often dominate a later, more aggressive and metastatic stage of the disease $(17,38)$. Hence, cell-cell contact and ECM composition are important characteristics of the inter- and intra-tumor heterogeneity to consider for therapy optimization $(39,40)$.

For our efforts to better understand CRC biology with particular emphasis on cell-cell-contact, we selected the presented CRC cell line panel with, at least partially, known morphological distinctions in 3D and known differences in the expression of E-cadherin/catenin complex proteins (26,41-44). Despite that fact that the DLD-1 and HCT-15 cells have been found to have the same genetic background (45), we intentionally examined these two cell lines for further proof in our study. As its original tumor, we also found two phenotypically distinct subpopulations of DLD-1 cells (26,28-31), which are epithelioid/cell cluster-forming/ $\alpha$-catenin-positive (DLD-1 ${ }^{\alpha \text {-cat }}$ ) versus round/single cell group-forming/ $\alpha$-catenin-negative (DLD-1 $\left.{ }^{\Delta \alpha-c a t}\right)$. It should be noted that EMT seemed not to occur according to our expression analysis of key EMT markers, such as fibronectin and TGF- $\beta$. Instead, the subcellular localization of E-cadherin changed from a membrane-associated to a peri-nuclear-associated one in the $\alpha$-catenin deficient subpopulation, while the E-cadherin and $\beta$-catenin protein levels were unaffected $(29,46)$. The loss of membranous E-cadherin and $\beta$-catenin is in agreement with cell-cell adhesion dysfunction observed in DLD-1 ${ }^{\Delta \alpha-\text { cat }}$ cells and could explain, at least in part, why the DLD-1 ${ }^{\Delta \alpha-\text { cat }}$ cells present a round morphology and grow as single cells in col-I. The underlying mechanisms may be that $\alpha$-catenin directly or indirectly anchors the E-cadherin/catenin protein complex to and stabilizes actin filaments as suggested by Abe and Takeichi (47). In addition to a cell-cell adhesion dysfunction, this could explain, at least partly, why DLD-1 $1^{\Delta \alpha-c a t}$ cells present a round morphology. For the transcriptional co-activator $\beta$-catenin, we observed, in contrast to previous studies $(20,30)$, no nuclear localization of $\beta$-catenin in either DLD-1 subpopulation. Causative may be our 3D matrix-based cell system, which differs from the work of others.

To provide even more genetic and transcriptional information, our genome and transcriptome analysis revealed several 
A

DNA Copy Number Changes

outer band: DLD-10-ant ; inner band: DLD-1 1 an-cat
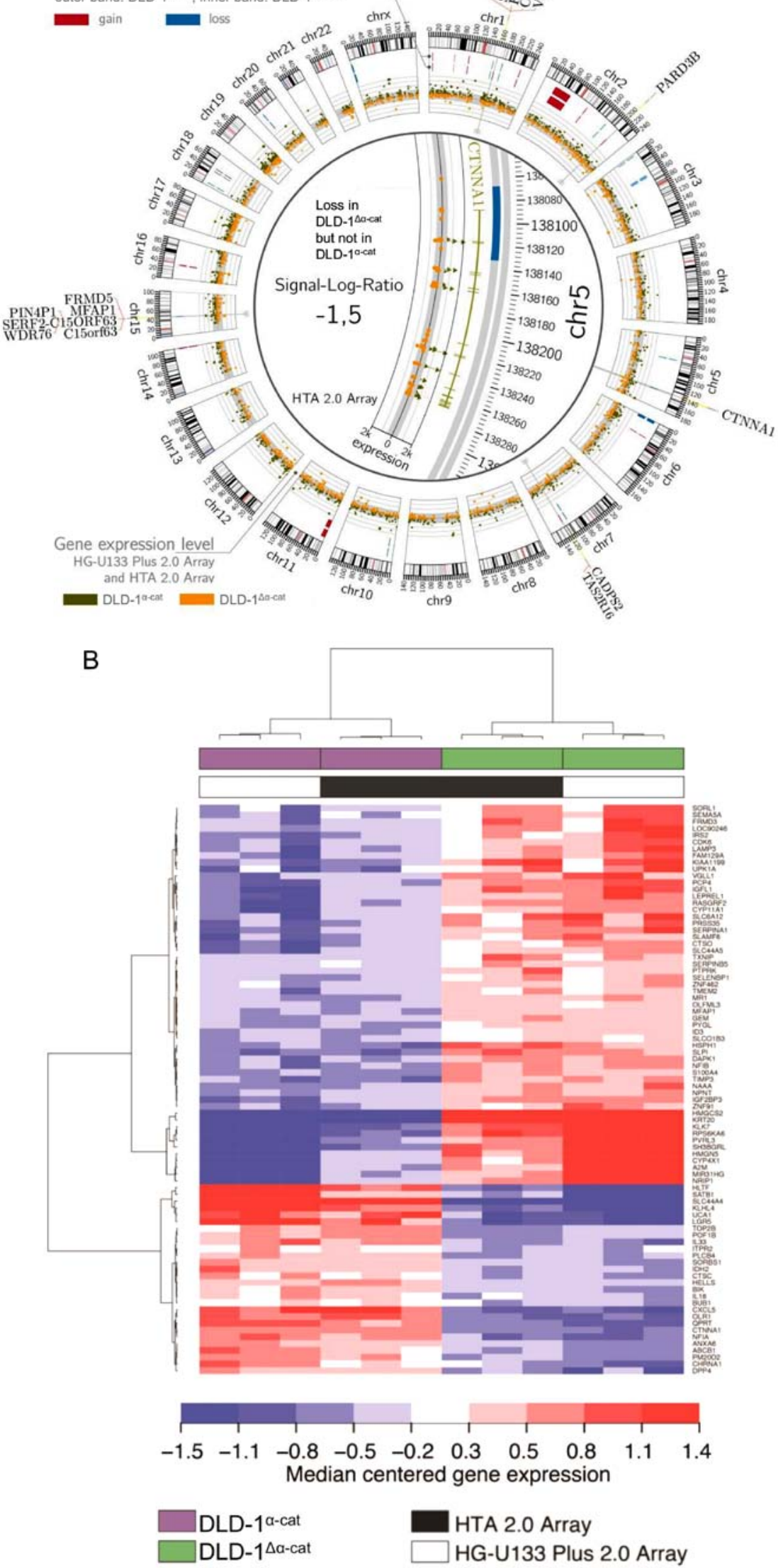

Figure 4. DLD-1 subpopulations cultured in three-dimensional (3D) col-I matrix display paired copy number abbreviations with altered gene expression. (A) Circos plot of copy number variations and transcriptome expression of DLD-1 subpopulations cultured in col-I. Inner circle shows gene expression levels of DLD-1 ${ }^{\alpha-c a t}$ cells (green) and DLD-1 ${ }^{\Delta \alpha-\text {-cat }}$ cells (yellow). Outer circle shows DNA copy number changes (gain in red, loss in blue). Outer and inner bands represent DLD-1 $1^{\alpha-c a t}$ and DLD-1 $1^{\Delta a-c a t}$ cells, respectively. Inset shows a magnification of chromosome 5. (B) Heatmap and clustering analysis of differentially expressed genes in DLD-1 subpopulations grown in col-I. Experiments were performed in triplicate using two independent array types. 
A

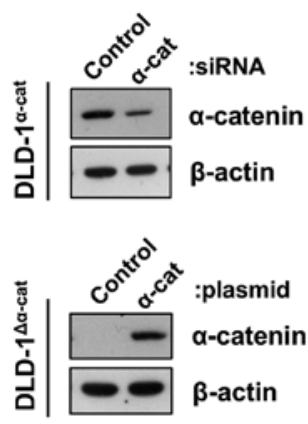

C
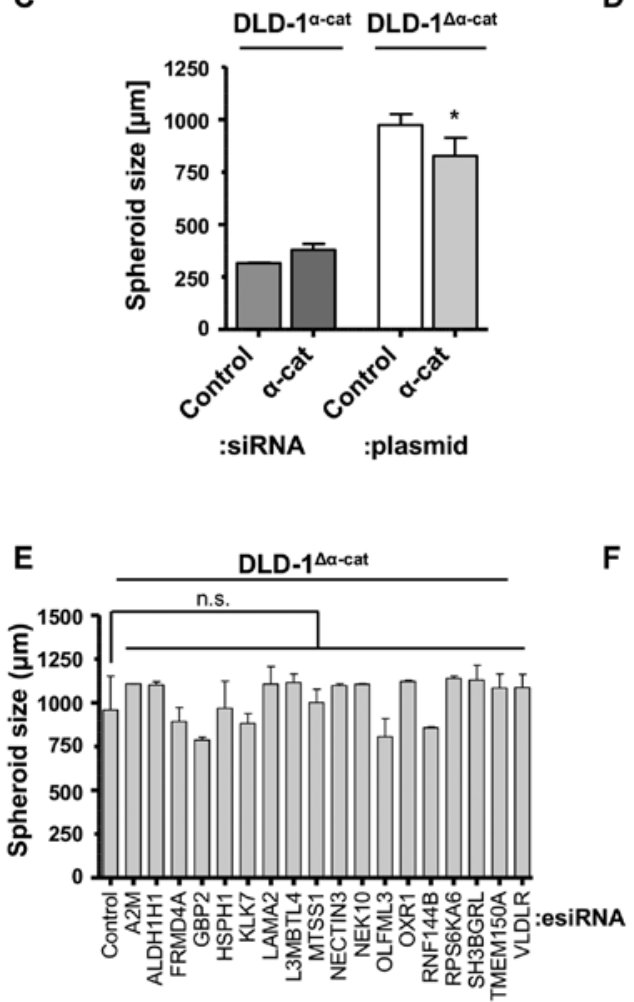

B

D

$\mathbf{F}$
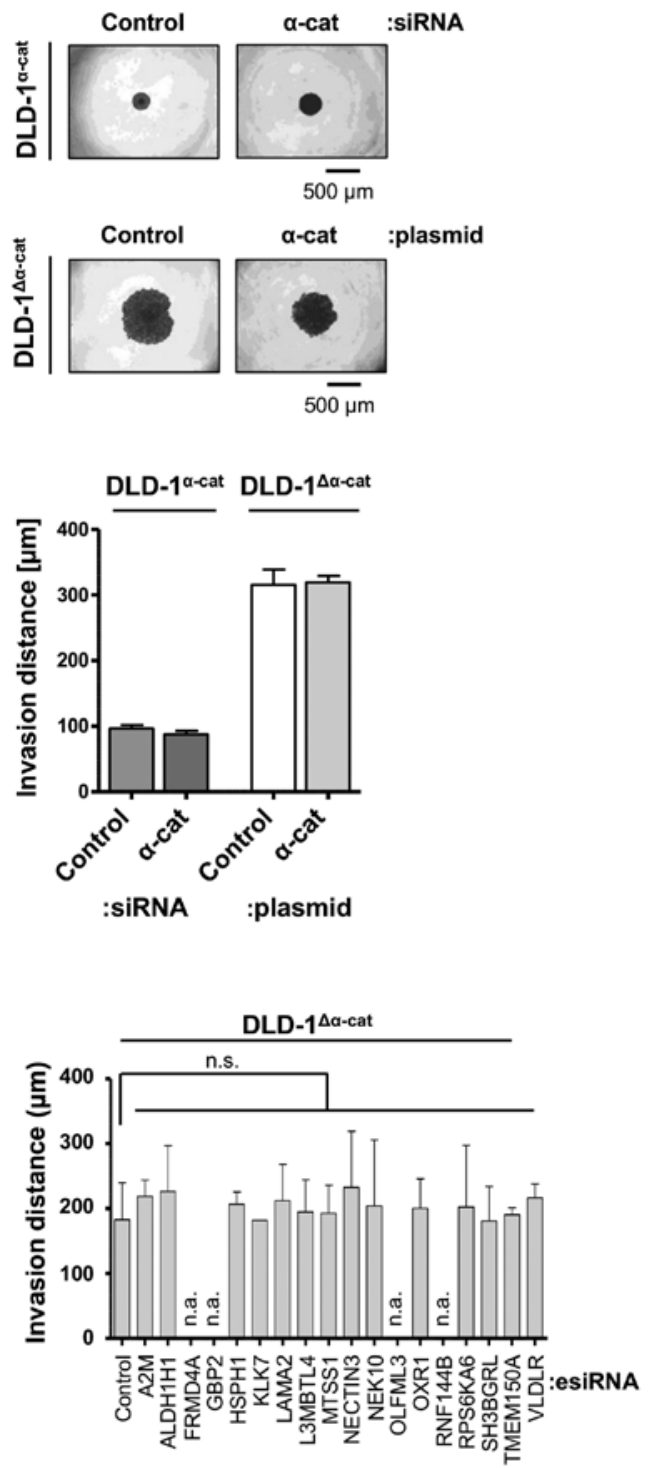

Figure 5. Effect of $\alpha$-catenin and upregulated genes in DLD-1 ${ }^{\Delta \alpha-c a t}$ cells on spheroid morphology and invasion. (A) Representative western blots of siRNA-mediated $\alpha$-catenin knockdown in DLD-1 ${ }^{\alpha-c a t}$ cells or reconstitution of $\alpha$-catenin in DLD-1 ${ }^{\Delta \alpha \text {-cat }}$ cells. (B) Representative phase-contrast images, (C) analysis of spheroid size and (D) invasion in col-I after $48 \mathrm{~h}$ after $\alpha$-catenin modulation. Experiments were performed in triplicate and the results represent the means \pm SD ( $\mathrm{P}<0.05$; n.s., not significant). Effect of esiRNA-mediated knockdown of upregulated genes in DLD-1 ${ }^{\alpha-c a t}$ cells on (E) spheroid size and (F) invasion in col-I after 48 h. Results represent the means \pm SD (n=2; n.s., not significant; n.a., not applicable due to spheroid instability).

differentially expressed genes in DLD-1 $1^{\Delta \alpha \text {-cat }}$ versus the DLD- ${ }^{\alpha-c a t}$ cells, including the $\beta$-catenin target genes, $S 100 A 4$, $L G R 5$ and $A B C B 1$ (48). Using bioinformatics analysis (such as cytoscape), no $\alpha$-catenin-dependent interactions between proteins of the E-cadherin/ $\beta$-catenin complex and the differentially expressed genes were found (data not shown).

Based on these clear genetic and transcriptional differences in the two DLD-1 cell populations, we tested for various endpoints. 3D matrix-based cultures of the DLD-1 ${ }^{\alpha-c a t}$ and DLD-1 $1^{\Delta \alpha-c a t}$ cells revealed similarities in adhesion, the proliferation rate, basal clonogenic survival and survival after single-dose X-ray irradiation or treatment with the chemotherapeutic agent, 5-FU. These observations are in contrast to reports showing the differential effects of irradiation and 5-FU on DLD-1 subpopulations $(28,49)$. Responsible, again, seem to be the well-known discrepancies between conventional 2D monolayer and more physiological 3D matrix-based cell cultures $(24,50,51)$. With regards to clinical relevance, it is important to point out that neither our, nor a previous study (28) analyzed the effects of dose fractionation on the survival of these two subpopulations. Thus, this gap needs to be closed in future experiments. Of note, and in line with $\alpha$-catenin silencing, the knockdown of E-cadherin failed to modify radiation survival in several other tested cell lines (A431, UT-SCC15, DLD-1, HCT-15 and HT-29) (52) (data not shown).

In addition to the above-mentioned endpoints, we measured $3 \mathrm{D}$ invasion into col-I. In agreement with the role of $\alpha$-catenin in invasion (26), the invasive capability of the DLD-1 ${ }^{\Delta \alpha-\text {-cat }}$ cells exceeded the one of DLD-1 ${ }^{\alpha-c a t}$ cells by $\sim 5$-fold. Intriguing to us was that we were unable to i) induce a clear switch in the morphological and invasive phenotype of the DLD-1 ${ }^{\Delta \alpha-c a t}$ cells by $\alpha$-catenin reconstitution; and ii) link the overexpressed genes detected in the DLD-1 ${ }^{\Delta \alpha \text {-cat }}$ cells through their knockdown 
A
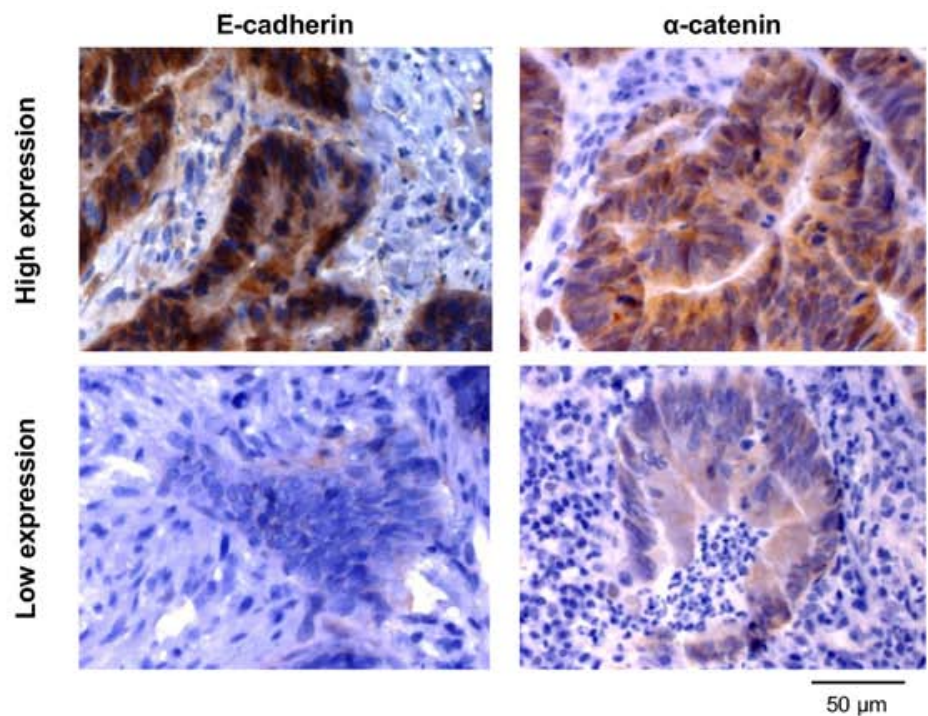

B
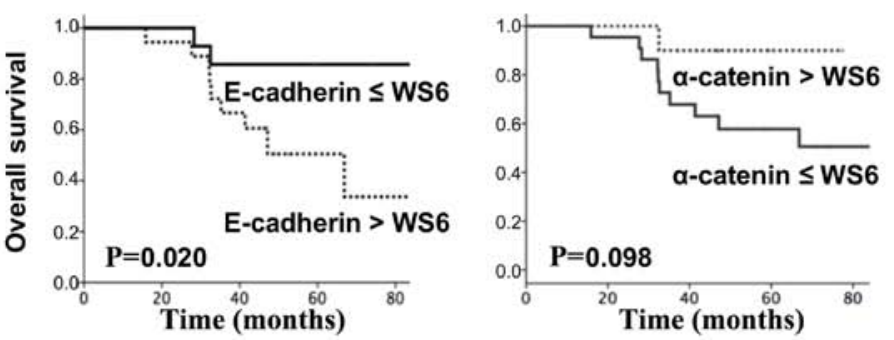

C
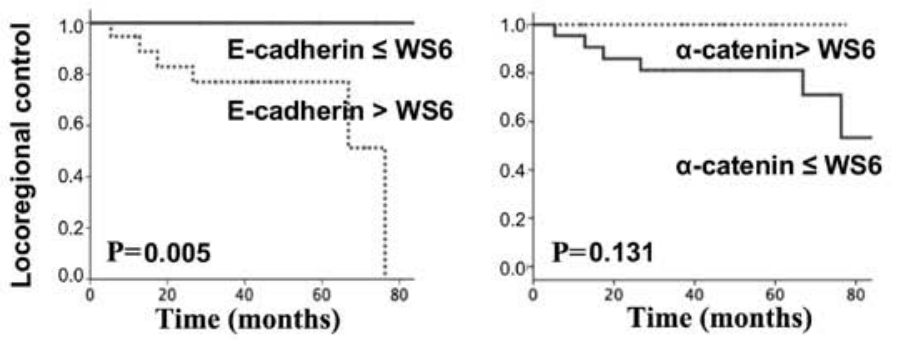

D
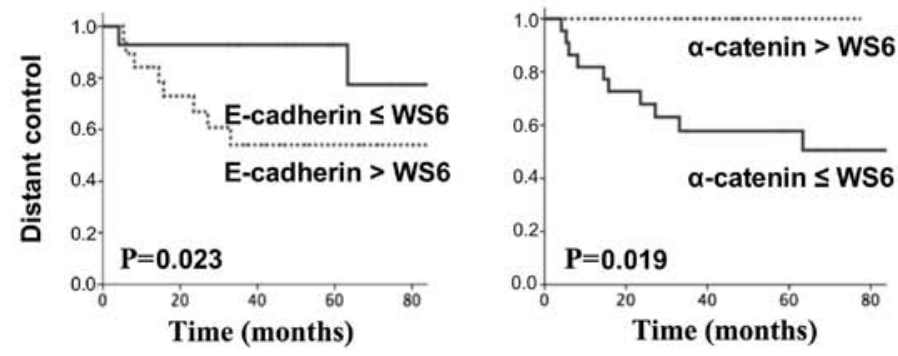

Figure 6. E-cadherin and $\alpha$-catenin inversely correlate with the prognosis of patients with rectal cancer. (A) Examples of rectal cancer biopsies with high and low immunohistochemical detection of E-cadherin and $\alpha$-catenin. Original magnification, $\mathrm{x} 400$; scale bar, $50 \mu \mathrm{m}$. (B) Cumulative incidence of overall survival, (C) locoregional failure and (D) distant failure according to a low E-cadherin and $\alpha$-catenin (individual WS $\leq 6$ ) expression vs. a high E-cadherin and $\alpha$-catenin (WS >6) expression in pretreatment biopsies of 33 patients with rectal carcinoma treated with neoadjuvant chemoradiotherapy.

functionally to morphology, spheroid formation and invasion. Vice versa, also the knockdown of $\alpha$-catenin in the DLD- $1^{\alpha-\text { cat }}$ cells failed to result in a clear switch to the invasive phenotype as observed in DLD-1 ${ }^{\Delta a-c a t}$ cells. Causative may be the incomplete knockdown mediated by siRNA in contrast to the complete genetic deletion in DLD-1 ${ }^{\Delta \alpha-\text {-cat }}$ cells. Mechanistically, $\alpha$-catenin dysfunction is likely to represent only one of the multiple facets in the interplay between cadherins, catenins and a plethora of cytoplasmic effectors like tyrosine kinases, protein tyrosine phosphatases and cytoskeletal regulators functioning in filament dynamics and cell polarity (53-55).

Another data set that requires further investigation came from our immunohistochemical analysis of $\alpha$-catenin and E-cadherin in patients with rectal cancer treated with neoadjuvant radiochemotherapy. In agreement with a low overall survival and low locoregional control, $\alpha$-catenin expression 
was low and correlated with these endpoints with a positive trend, while it significantly correlated with a lower distant control. E-cadherin expression, by contrast, was high and significantly correlated with these three clinical endpoints in an inverse manner relative to $\alpha$-catenin.

In conclusion, our data indicate that $\alpha$-catenin is partially involved in CRC cell invasion via yet to be determined mechanisms. Although one might anticipate a multiplicity of effects by adhesive dysfunctions, it is astonishing to detect that, if at all, only very minor modifications can be found in biologically and clinically relevant endpoints such as proliferation and therapy sensitivity. Owing to fundamental processes orchestrated in both cancer and normal cells through cell-cell adhesion, it remains challenging to identify novel potential cancer targets in cell-cell contacts. Further studies are warranted to better understand the molecular circuitry how cadherins and catenins promote tumorigenesis and resistance.

\section{Acknowledgements}

The authors are grateful to Dr J. Cinatl (University of Frankfurt, Germany) for providing the SW620 and SW837 cells and to Dr C. Gottardi (Northwestern University, Chicago, USA) for providing the pcDNA3- $\alpha$-cat plasmid. The authors would also like to thank Mrs. I. Lange, Mrs. J. Singh-Müller and Mr. J. Oppermann for their excellent technical assistance.

\section{Funding}

The study and authors were in part supported by the EFRE Europäische Fonds für regionale Entwicklung, Europa fördert Sachsen (100066308).

\section{Availability of data and materials}

The analyzed datasets generated during the study are available from the corresponding author on reasonable request.

\section{Authors' contributions}

NC conceived and designed the study; SF performed the cell culture experiments; $\mathrm{SH}$ performed the immunohistochemical analysis on patient material; BO performed and analyzed the genomics and transcriptomics experiments; FR supplied the patient survival data; all authors wrote and edited and have approved the manuscript.

\section{Ethics approval and consent to participate}

This study was approved by the Ethics Committee of the University of Erlangen (approval no. 3085). Each patient provided written informed consent before being accrued.

\section{Consent for publication}

Not applicable.

\section{Competing interests}

The authors declare that they have no competing interests.

\section{References}

1. Kuipers EJ, Grady WM, Lieberman D, Seufferlein T, Sung JJ, Boelens PG, van de Velde CJ and Watanabe T: Colorectal cancer. Nat Rev Dis Primers 1: 15065, 2015.

2. Stein A and Bokemeyer C: How to select the optimal treatment for first line metastatic colorectal cancer. World J Gastroenterol 20: 899-907, 2014.

3. Canel M, Serrels A, Frame MC and Brunton VG: E-cadherinintegrin crosstalk in cancer invasion and metastasis. J Cell Sci 126: 393-401, 2013.

4. van Roy F and Berx G: The cell-cell adhesion molecule E-cadherin. Cell Mol Life Sci 65: 3756-3788, 2008.

5. Raftopoulos I, Davaris P, Karatzas G, Karayannacos P and Kouraklis G: Level of alpha-catenin expression in colorectal cancer correlates with invasiveness, metastatic potential, and survival. J Surg Oncol 68: 92-99, 1998.

6. Filiz AI, Senol Z, Sucullu I, Kurt Y, Demirbas S and Akin ML: The survival effect of E-cadherin and catenins in colorectal carcinomas. Colorectal Dis 12: 1223-1230, 2010.

7. Chen X, Wang Y, Xia H, Wang Q, Jiang X, Lin Z, Ma Y, Yang Y and $\mathrm{Hu} \mathrm{M}$ : Loss of E-cadherin promotes the growth, invasion and drug resistance of colorectal cancer cells and is associated with liver metastasis. Mol Biol Rep 39: 6707-6714, 2012.

8. Christou N, Perraud A, Blondy S, Jauberteau MO, Battu S and Mathonnet M: E-cadherin: A potential biomarker of colorectal cancer prognosis. Oncol Lett 13: 4571-4576, 2017.

9. Kwok TT and Sutherland RM: The influence of cell-cell contact on radiosensitivity of human squamous carcinoma cells. Radiat Res 126: 52-57, 1991.

10. Moussa H, Mitchell SA, Grénman R and Joiner MC: Cell-cell contact increases radioresistance in head and neck carcinoma cell lines. Int J Radiat Biol 76: 1245-1253, 2000.

11. Meineke V, Gilbertz KP, Schilperoort K, Cordes N, Sendler A, Moede $\mathrm{T}$ and van Beuningen D: Ionizing radiation modulates cell surface integrin expression and adhesion of COLO-320 cells to collagen and fibronectin in vitro. Strahlenther Onkol 178: 709-714, 2002.

12. Cordes N, Hansmeier B, Beinke C, Meineke V and van Beuningen D: Irradiation differentially affects substratumdependent survival, adhesion, and invasion of glioblastoma cell lines. Br J Cancer 89: 2122-2132, 2003.

13. Ni J, Cozzi P, Hao J, Beretov J, Chang L, Duan W, Shigdar S, Delprado W, Graham P, Bucci J, et al: Epithelial cell adhesion molecule (EpCAM) is associated with prostate cancer metastasis and chemo/radioresistance via the PI3K/Akt/mTOR signaling pathway. Int J Biochem Cell Biol 45: 2736-2748, 2013.

14. Yuan D, Chen L, Li M, Xia H, Zhang Y, Chen T, Xia R, Tang Q, Gao F, Mo X, et al: Isolation and characterization of circulating tumor cells from human gastric cancer patients. J Cancer Res Clin Oncol 141: 647-660, 2015.

15. Coulson-Thomas VJ, Coulson-Thomas YM, Gesteira TF, de Paula CA, Mader AM, Waisberg J, Pinhal MA, Friedl A, Toma L and Nader HB: Colorectal cancer desmoplastic reaction up-regulates collagen synthesis and restricts cancer cell invasion. Cell Tissue Res 346: 223-236, 2011.

16. Mylonas CC and Lazaris AC: Colorectal cancer and basement membranes: Clinicopathological correlations. Gastroenterol Res Pract 2014: 580159, 2014

17. Vellinga TT, den Uil S, Rinkes IHB, Marvin D, Ponsioen B, Alvarez-Varela A, Fatrai S, Scheele C, Zwijnenburg DA, Snippert H, et al: Collagen-rich stroma in aggressive colon tumors induces mesenchymal gene expression and tumor cell invasion. Oncogene 35: 5263-5271, 2016.

18. Eke I, Koch U, Hehlgans S, Sandfort V, Stanchi F, Zips D, Baumann M, Shevchenko A, Pilarsky C, Haase M, et al: PINCH1 regulates Akt1 activation and enhances radioresistance by inhibiting PP1alpha. J Clin Invest 120: 2516-2527, 2010.

19. Poschau M, Dickreuter E, Singh-Müller J, Zscheppang K, Eke I, Liersch $\mathrm{T}$ and Cordes N: EGFR and $\beta 1$-integrin targeting differentially affect colorectal carcinoma cell radiosensitivity and invasion. Radiother Oncol 116: 510-516, 2015.

20. Daugherty RL, Serebryannyy L, Yemelyanov A, Flozak AS, Yu HJ, Kosak ST, deLanerolle P and Gottardi CJ: $\alpha$-Catenin is an inhibitor of transcription. Proc Natl Acad Sci USA 111: 5260-5265, 2014.

21. Zschenker O, Streichert T, Hehlgans S and Cordes N: Genome-wide gene expression analysis in cancer cells reveals $3 \mathrm{D}$ growth to affect ECM and processes associated with cell adhesion but not DNA repair. PLoS One 7: e34279, 2012. 
22. Rödel C, Liersch T, Hermann RM, Arnold D, Reese T, Hipp M, Fürst A, Schwella N, Bieker M, Hellmich G, et al: Multicenter phase II trial of chemoradiation with oxaliplatin for rectal cancer. J Clin Oncol 25: 110-117, 2007.

23. Schlingemann J, Habtemichael N, Ittrich C, Toedt G, Kramer H Hambek M, Knecht R, Lichter P, Stauber R and Hahn M: Patient-based cross-platform comparison of oligonucleotide microarray expression profiles. Lab Invest 85: 1024-1039, 2005.

24. Bissell MJ, Kenny PA and Radisky DC: Microenvironmental regulators of tissue structure and function also regulate tumor induction and progression: The role of extracellular matrix and its degrading enzymes. Cold Spring Harb Symp Quant Biol 70: 343-356, 2005.

25. Kenny PA, Lee GY, Myers CA, Neve RM, Semeiks JR, Spellman PT, Lorenz K, Lee EH, Barcellos-Hoff MH, Petersen OW, et al: The morphologies of breast cancer cell lines in three-dimensional assays correlate with their profiles of gene expression. Mol Oncol 1: 84-96, 2007.

26. Vermeulen SJ, Bruyneel EA, Bracke ME, De Bruyne GK, Vennekens KM, Vleminckx KL, Berx GJ, van Roy FM and Mareel MM: Transition from the noninvasive to the invasive phenotype and loss of alpha-catenin in human colon cancer cells. Cancer Res 55: 4722-4728, 1995.

27. Zeisberg $M$ and Neilson EG: Biomarkers for epithelial-mesenchymal transitions. J Clin Invest 119: 1429-1437, 2009

28. Dexter DL, Spremulli EN, Fligiel Z, Barbosa JA, Vogel R, VanVoorhees A and Calabresi P: Heterogeneity of cancer cells from a single human colon carcinoma. Am J Med 71: 949-956, 1981.

29. Plumb CL, Adamcic U, Shahrzad S, Minhas K, Adham SA and Coomber BL: Modulation of the tumor suppressor protein alpha-catenin by ischemic microenvironment. Am J Pathol 175 $1662-1674,2009$.

30. Giannini AL, Vivanco M and Kypta RM: alpha-catenin inhibits beta-catenin signaling by preventing formation of a beta-catenin*T-cell factor*DNA complex. J Biol Chem 275 21883-21888, 2000

31. Takaya Y, Tanaka K, Hirakawa C, Tagawa Y and Niwa M: New method for separation of subpopulations from a heterogeneous colon cancer cell line. Anticancer Res 28: 3665-3670, 2008.

32. Huber O and Petersen I: 150th Anniversary Series: Desmosomes and the hallmarks of cancer. Cell Commun Adhes 22: 15-28, 2015.

33. Rodriguez FJ, Lewis-Tuffin LJ and Anastasiadis PZ: E-cadherin's dark side: Possible role in tumor progression. Biochim Biophys Acta 1826: 23-31, 2012.

34. Lee CC, Chen WS, Chen CC, Chen LL, Lin YS, Fan CS and Huang TS: TCF12 protein functions as transcriptional repressor of E-cadherin, and its overexpression is correlated with metastasis of colorectal cancer. J Biol Chem 287: 2798-2809, 2012

35. Chen X, Zhu H, Wu X, Xie X, Huang G, Xu X, Li S and Xing C: Downregulated pseudogene CTNNAP1 promote tumor growth in human cancer by downregulating its cognate gene CTNNA1 expression. Oncotarget 7: 55518-55528, 2016.

36. Peng J, Qi S, Wang P, Li W, Song L, Liu C and Li F: Meta-analysis of downregulated E-cadherin as a poor prognostic biomarker for cervical cancer. Future Oncol 12: 715-726, 2016.

37. Rajwar YC, Jain N, Bhatia G, Sikka N, Garg B and Walia E: Expression and significance of cadherins and its subtypes in development and progression of oral cancers: A review. J Clin Diagn Res 9: ZE05-ZE07, 2015.

38. Daneker GW Jr, Mercurio AM, Guerra L, Wolf B, Salem RR, Bagli DJ and Steele GD Jr: Laminin expression in colorectal carcinomas varying in degree of differentiation. Arch Surg 122: 1470-1474, 1987.

39. Burrell RA, McGranahan N, Bartek J and Swanton C: The causes and consequences of genetic heterogeneity in cancer evolution. Nature 501: 338-345, 2013.
40. Fouad YA and Aanei C: Revisiting the hallmarks of cancer. Am J Cancer Res 7: 1016-1036, 2017.

41. Ireton RC, Davis MA, van Hengel J, Mariner DJ, Barnes K, Thoreson MA, Anastasiadis PZ, Matrisian L, Bundy LM, Sealy L, et al: A novel role for p1 20 catenin in E-cadherin function. J Cell Biol 159: 465-476, 2002

42. El-Bahrawy M, Poulsom R, Rowan AJ, Tomlinson IT, Alison MR, Poulsom SR and Tomlinson IT: Characterization of the E-cadherin/catenin complex in colorectal carcinoma cell lines. Int J Exp Pathol 85: 65-74, 2004.

43. Luca AC, Mersch S, Deenen R, Schmidt S, Messner I, Schäfer KL, Baldus SE, Huckenbeck W, Piekorz RP, Knoefel WT, et al: Impact of the 3D microenvironment on phenotype, gene expression, and EGFR inhibition of colorectal cancer cell lines. PLoS One 8: e59689, 2013.

44. Ludwig K, Tse ES and Wang JY: Colon cancer cells adopt an invasive phenotype without mesenchymal transition in 3-D but not 2-D culture upon combined stimulation with EGF and crypt growth factors. BMC Cancer 13: 221, 2013.

45. Vermeulen SJ, Chen TR, Speleman F, Nollet F, Van Roy FM and Mareel MM: Did the four human cancer cell lines DLD-1, HCT-15, HCT-8, and HRT-18 originate from one and the same patient? Cancer Genet Cytogenet 107: 76-79, 1998

46. Piao H-L, Yuan Y, Wang M, Sun Y, Liang H and Ma L: $\alpha$-catenin acts as a tumour suppressor in E-cadherin-negative basal-like breast cancer by inhibiting NF- $\mathrm{KB}$ signalling. Nat Cell Biol 16: 245-254, 2014.

47. Abe $\mathrm{K}$ and Takeichi M: EPLIN mediates linkage of the cadherin catenin complex to F-actin and stabilizes the circumferential actin belt. Proc Natl Acad Sci USA 105: 13-19, 2008.

48. Herbst A, Jurinovic V, Krebs S, Thieme SE, Blum H, Göke B and Kolligs FT: Comprehensive analysis of $\beta$-catenin target genes in colorectal carcinoma cell lines with deregulated Wnt/ $\beta$-catenin signaling. BMC Genomics 15: 74, 2014

49. Leith JT, Dexter DL, DeWyngaert JK, Zeman EM, Chu MY, Calabresi P and Glicksman AS: Differential responses to $\mathrm{X}$-irradiation of subpopulations of two heterogeneous human carcinomas in vitro. Cancer Res 42: 2556-2561, 1982.

50. Eke I and Cordes N: Radiobiology goes 3D: How ECM and cell morphology impact on cell survival after irradiation. Radiother Oncol 99: 271-278, 2011.

51. Eke I, Hehlgans S, Zong Y and Cordes N: Comprehensive analysis of signal transduction in three-dimensional ECM-based tumor cell cultures. J Biol Methods 2: 31, 2015.

52. Mazzeo E, Hehlgans S, Valentini V, Baumann M and Cordes N: The impact of cell-cell contact, E-cadherin and EGF receptor on the cellular radiosensitivity of A431 cancer cells. Radiat Res 178: 224-233, 2012.

53. Perez-Moreno M, Jamora C and Fuchs E: Sticky business: Orchestrating cellular signals at adherens junctions. Cell 112: 535-548, 2003.

54. Mège RM, Gavard J and Lambert M: Regulation of cell-cell junctions by the cytoskeleton. Curr Opin Cell Biol 18: 541-548, 2006.

55. Jeanes A, Gottardi CJ and Yap AS: Cadherins and cancer: How does cadherin dysfunction promote tumor progression? Oncogene 27: 6920-6929, 2008. International (CC BY-NC-ND 4.0) License. 